\title{
Water retention curves of lightweight cemented soils
}

\author{
Enza Vitale ${ }^{1, *}$, Olivier Cuisinier ${ }^{2}$, Giacomo Russo ${ }^{3}$,Dimitri Deneele ${ }^{4}$, Domenico De Sarno ${ }^{5}$, Marco Valerio Nicotera ${ }^{5}$, \\ Raffaele Papa ${ }^{6}$ and Gianfranco Urciuoli ${ }^{5}$ \\ ${ }^{1}$ Department of Civil and Mechanical Engineering, University of Cassino and Southern Lazio, Italy \\ ${ }^{2}$ LEMTA, UMR 7563 - Université de Lorraine - CNRS, Nancy, France \\ ${ }^{3}$ Department of Earth Science, Environment and Resources, University of Napoli Federico II, Italy \\ ${ }^{4}$ Institut des Matériaux Jean Rouxel (IMN), Université de Nantes, CNRS, France \\ ${ }^{5}$ Department of Civil, Architectural and Environmental Engineering (DICEA), University of Napoli Federico II, Italy \\ ${ }^{6}$ Terre Leggere Ltd.
}

\begin{abstract}
In the present paper an experimental investigation on water retention properties of lightweight cemented soils (LWCS) taking into account the effects of air foam content and curing time is presented. This experimental study, aimed at determining the suction range corresponding to significant changes in water content, is preliminary to future investigations devoted to durability properties of LWCS systems against wetting and drying cycles. Test results showed that water retention capacity is slightly affected by the curing time for the considered time interval (i.e. 30 and 90 days). Furthermore, the addition of air foam does not affect water retention properties of treated samples. Large voids are present in the samples as footprints of air bubbles added upon mixing, leading to an increase of the porosity of samples without altering the microstructure of the matrix.
\end{abstract}

\section{Introduction}

The use of natural soils not suitable for construction purposes as lightweight cemented soils represents an increasingly innovative technology in the framework of a sustainable geotechnical engineering design. Lightweight cemented soils (LWCS), obtained by adding air foam to soil-cement-water mixture to have a low density and self-levelling fresh mixture, are advantageously used for different earthworks, such as cavities filling, trench backfilling, embankment construction [1-4]. The material is transferred by pumping from the batch plant to the construction site because of its high fluidity, and it is placed without compaction, thus reducing construction time.

Several studies on the effects of cement, foam and initial water content on unit weight and shear strength of LWCS have been developed, shedding light on the evolution of physical and mechanical properties as a function of treatment parameters [5-12]. An insight into the role of foam content on chemo-physical evolution and microstructural features of the soil-cement-water system on mechanical behaviour of LWCSs have been recently provided by Vitale et al. 2019 [13]. They highlighted that addition of foam does not alter chemophysical evolution of the soil-cement-water system in terms of either cement hydration or pozzolanic reactions. Addition of foam introduces air into the system included in bubbles of different sizes, increasing system porosity. The effect of porosity on the mechanical behaviour upon shearing induces an overall reduction of shear strength and a transition from brittle and dilative behaviour to ductile and contractile behaviour, as detected for samples with the highest foam content. The observed behaviour was consistent with the expected behaviour of loose and dense samples of the same natural soil, where the initial physical state (i.e. void ratio) governs the mechanical response upon shearing.

Durability of LWCS under different environmental loads have not been thoroughly investigated in literature, even if it represents a relevant aspect for an extensive use of the improvement technique in geotechnical practice. This experimental study is focused on the modification induced by the addition of cement and foam on the water retention properties of a treated clay. The water retention properties are fundamental to the understanding of the hydro-mechanical behaviour of unsaturated samples [14-15]. Water retention curves have been determined for a kaolin treated with cement and different percentages of added foam by osmotic technique. The comparison of the water retention curves of treated samples prepared at increasing foam content and cured for increasing time intervals has been reported. The link between water retention properties determined at volume scale and microstructural features of LWCS has been discussed. This stage of the experimental work is preliminary to the future development devoted to durability of LWCS subjected to wetting and drying cycles.

*orresponding author: e.vitale@unicas.it 


\section{Materials and methods}

\subsection{Materials}

A highly refined kaolin (Speswhite kaolin, Imerys Minerals, UK) from deposits in the Southwest of England was used. The specific gravity is $\mathrm{G}_{\mathrm{s}}=2.6$, and the surface area determined by nitrogen adsorption (BET) is $14 \mathrm{~m}^{2} / \mathrm{g}$. The $\mathrm{pH}$ value of the clay is about 4.6 . The liquid and plastic limits are $70 \%$ and $32 \%$, respectively, with a plastic index IP of $38 \%$. The sample is mainly formed by kaolinite clay minerals with a small amount of quartz and muscovite.

Portland limestone cement (CEM II/A-LL 42.5R) supplied by Buzzi Unicem, Italy, was used for the treatment. The material consists of a main phase of a cement alite $\left(\mathrm{C}_{3} \mathrm{~S}\right)$, belite $\left(\mathrm{C}_{2} \mathrm{~S}\right)$, aluminate $\left(\mathrm{C}_{3} \mathrm{~A}\right)$, ferrite phases $\left(\mathrm{C}_{4} \mathrm{AF}\right)$ and calcite $\left(\mathrm{CaCO}_{3}\right)$ with a small amount of gypsum.

ISOCEM S/L was the foaming agent used in the present work supplied by Isoltech srl, Italy. It is a viscous liquid with a $\mathrm{pH}$ of approximately 7.5-9 composed of natural surfactants mixed with plant-based raw materials. The foaming agent for the production of lightweight cemented samples was used at a percentage of $2.5 \%$.

\subsection{Samples preparation}

Cement treated samples were prepared by mixing soil with water to slurry at approximately twice the liquid limit (i.e. $2 \mathrm{w}_{\mathrm{L}}=140 \%$ ) and dry cement with water at a water/ cement (w/c) ratio of 0.5 . Forty per cent cement by dry weight of soil was selected for the treatment. Lightweight cemented samples were prepared by introducing a preformed foam, made by pressurizing an aqueous solution of foaming agent with compressed air, into soil-cement-water slurry and mixing for $1 \mathrm{~min}$ with an electric agitator. A density of $75 \mathrm{~g} / \mathrm{L}$ was selected for the preformed foam. Selected foam contents for lightweight cemented samples were $20 \%$ and $40 \%$ by volume of the mixture $(\mathrm{V})$. The amount of foam added to the soil-cement-water slurry was determined as follows:

$$
\begin{gathered}
V_{f}=V-V_{c}-V_{s}-V_{w}=\frac{V_{f}}{n_{f}}-V_{c}-V_{s}-V_{w} \\
\Rightarrow V_{f}=\left(\frac{n_{f}}{1-n_{f}}\right)\left(V_{s}+V_{c}+V_{w}\right)
\end{gathered}
$$

where $n_{f}$ is the ratio of volume of foam and volume of mixture $\left(n_{f}=V_{f} / V\right), V_{s}$ is the volume of solids, $V_{c}$ is the volume of cement, and $V_{w}$ is the volume of water. Treated samples were poured into moulds without compaction and then sealed in plastic bags and cured at room temperature for increasing curing times before performing tests. A curing time interval ranging from 30 up to 90 days was considered in the experimental program. A scheme of the mix design is shown in Figure 1. In the Table 1 a summary of the initial condition of treated samples is reported. Denomination of the samples indicates the cement content and the foam content (e.g.
KC40\%_20\%V means kaolin with $40 \%$ of cement and $20 \%$ of foam).

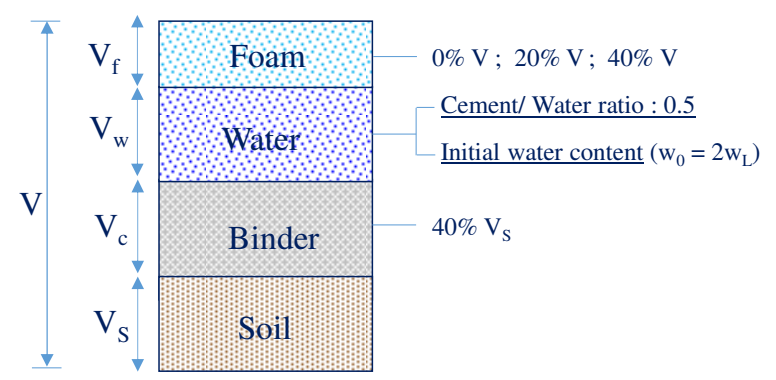

Fig. 1. Relation between phases for sample preparation.

Table 1. Summary of the initial conditions of treated samples

\begin{tabular}{|c|c|c|c|}
\hline ID sample & $\begin{array}{c}\boldsymbol{v} \\
{\left[\mathbf{k N} / \mathbf{m}^{3}\right]}\end{array}$ & $\begin{array}{c}\boldsymbol{V}_{\mathbf{d}} \\
{\left[\mathbf{k N} / \mathbf{m}^{3}\right]}\end{array}$ & $\begin{array}{c}\mathbf{e} \\
{[-]}\end{array}$ \\
\hline $\mathrm{KC} 40 \%$ & 14,0 & 6,8 & 2,8 \\
\hline $\mathrm{KC} 40 \% \_20 \% \mathrm{~V}$ & 12,5 & 6,1 & 3,3 \\
\hline $\mathrm{KC} 40 \% \_40 \% \mathrm{~V}$ & 10,3 & 5,0 & 4,2 \\
\hline
\end{tabular}

\subsection{Experimental procedures}

The water retention curves were determined over a wide suction range ( 0 to $292 \mathrm{MPa}$ ) by combining the osmotic technique and the salt solution method.

In the osmotic method, each sample was placed in a semi-permeable membrane, that is then immersed in a solution of macromolecules. This membrane prevents the macromolecules from moving towards the sample but allows water exchange. This exchange of water is due to the process of osmosis. Water movements and thus suction variations are controlled by the osmosis phenomenon: the higher the solution concentration, the higher the applied suction. This method was employed up to a suction of $8 \mathrm{MPa}$. Moisture content equilibrium was typically reached after 1 week. In the saturated salt solution technique, the soil sample was introduced into an airtight chamber where the relative humidity is maintained constant with a salt solution. The soil sample absorbs or desorbs water vapour until equilibrium is reached. Different solutions were employed to impose suctions up to $292 \mathrm{MPa}$. Moisture content equilibrium was typically reached after 2 weeks. More details about those methods can be found in Stoltz et al. (2012) [16]. After equilibrium, the moisture content of the samples was determined. Their total suction was also checked using a dew-point potentiometer (WP4C®). The dimensions of each sample were also measured.

Thermogravimetric analysis (TGA) was performed with a Netzsch STA 449F3 Jupiter, equipped with a mass spectrometer. The finely ground sample was heated at a rate of $10^{\circ} \mathrm{C} \mathrm{min}{ }^{-1}$, under argon atmosphere, from 
ambient temperature to $1000{ }^{\circ} \mathrm{C}$. Netzsch Proteus software was used to process the results.

Microstructural and morphological features of cement treated and lightweight samples were observed through SU5000 Hitachi Scanning Electron Microscopy (SEM). SEM observations were performed on gold coated samples, previously dehydrated by freeze-drying technique.

\section{Results}

Water retention curves of cement treated samples (KC40\%) as function of curing time are reported in Figure 2. In the low suction range, slight differences are detected for 30 and 90 days cured samples. Nevertheless, treated samples show a similar behaviour in the higher suction range (suction $>7 \mathrm{MPa}$ ). The observed behaviours are consistent with chemo-physical evolution of the system. Quantitative interpretations of TGA for cement treated and lightweight cemented samples after $24 \mathrm{~h}, 7,28,60$ and 90 days of curing are reported in Figure 3. Precipitation of hydrated phases due to cement hydration and pozzolanic reactions takes place within the first 28 days of curing. For longer curing time, the increase of mass loss attributed to formation of cementitious compound is negligible

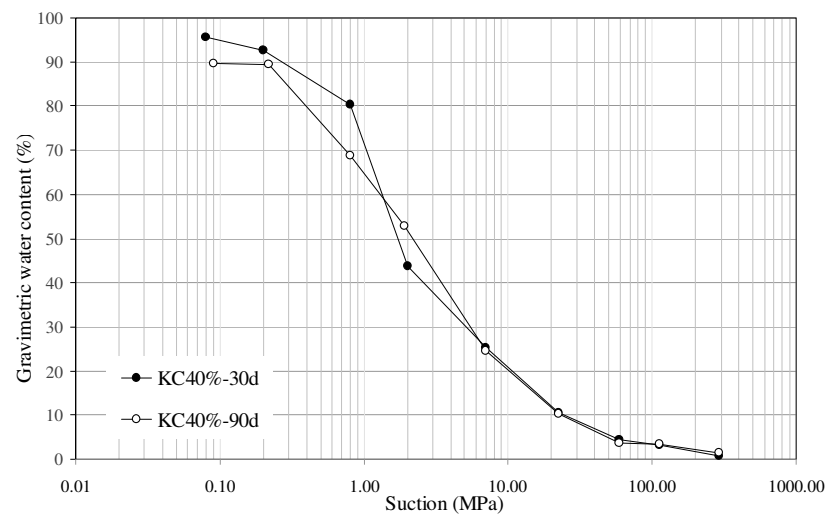

Fig. 2. Water retention curves of cement treated samples (KC40\%) after 30 days and 90 days of curing.

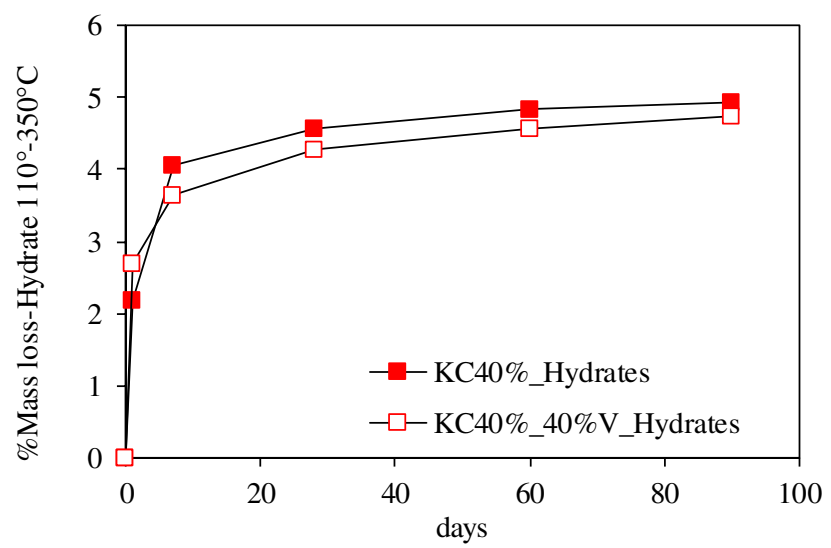

Fig. 3. Quantitative interpretation of TGAs of $\mathrm{KC} 40 \%$ and $\mathrm{KC} 40 \% \_40 \% \mathrm{~V}$ : evolution of hydrates with curing time.

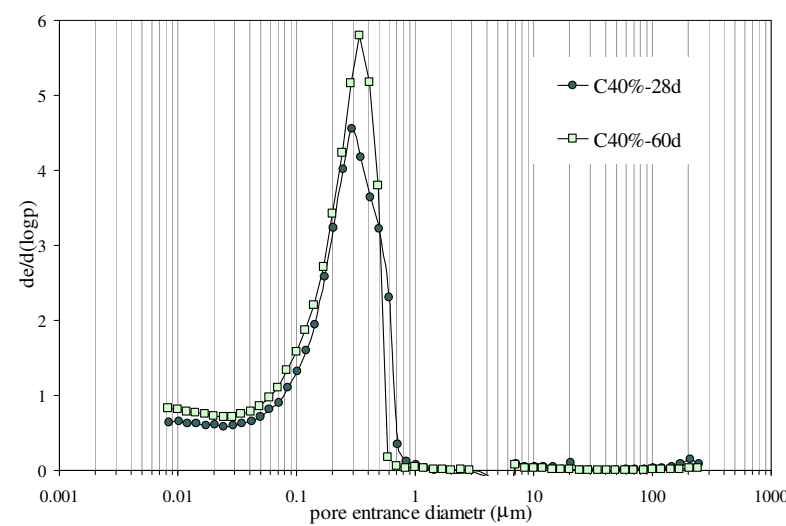

Fig. 4. Pore size distribution of cement treated samples (KC40\%) after 28 days and 60 days of curing (adapted by [13]).

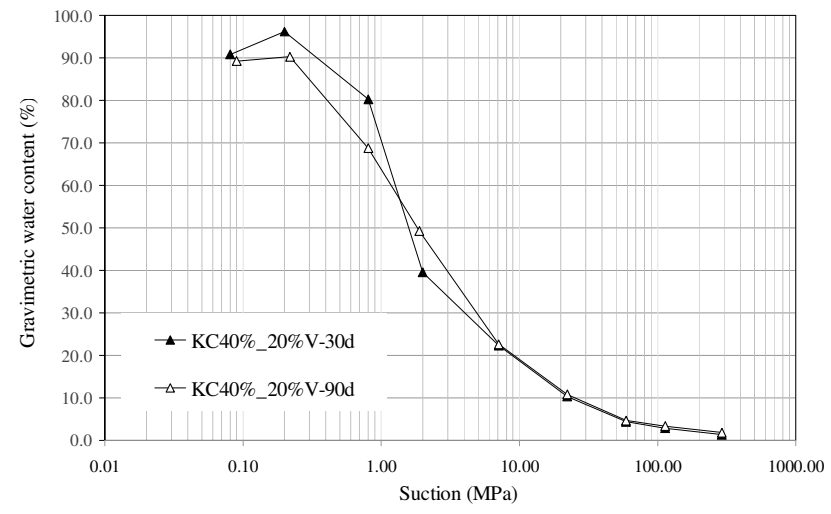

Fig. 5. Water retention curves of lightweight cemented samples (KC40\%_20\%V) after 30 days and 90 days of curing.

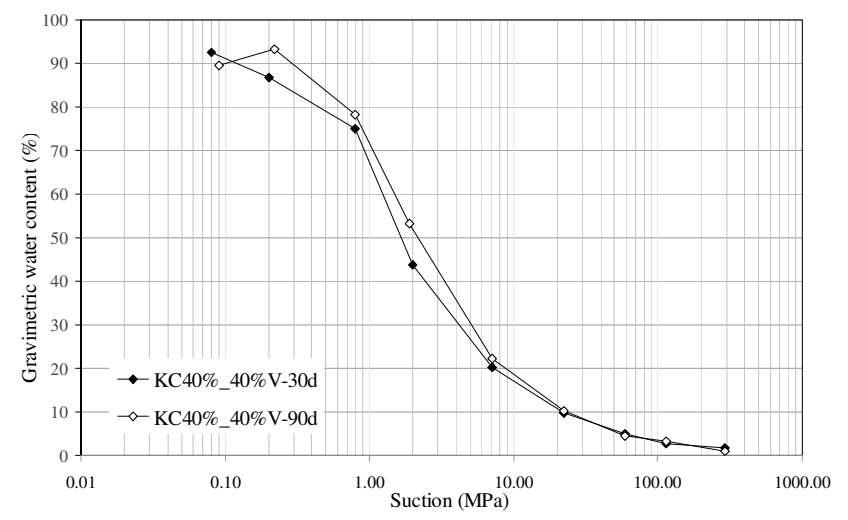

Fig. 6. Water retention curves of lightweight cemented samples (KC40\%_40\% V) after 30 days and 90 days of curing.

As a consequence, the microstructure of the treated soils undergoes slight modifications during this time interval, as evidenced by [13] comparing the pore size distributions determined by Mercury Intrusion Porosimetry technique performed on lightweight cemented samples at increasing curing times.

Water retention curves of treated soils are then slightly affected by curing time in the considered time interval. The overlap of the retention curves in the suction range greater than $7 \mathrm{MPa}$ is consistent with the 
overlap of the pore size distribution curves showed by the treated samples in the range of the smallest pores (pore entrance diameter under $0.2 \mu \mathrm{m}$ ), as shown in Figure 4, mainly associated to the porosity of the cement hydrated phases.

The effects of foam addition on water retention properties of cement treated samples have been also investigated. Addition of foam does not alter the chemophysical evolution of soil-cement-water system in terms of either cement hydration or pozzolanic reactions. Water retention curves of lightweight cemented samples prepared at different foam contents as function of curing time are reported in Figure 5 and Figure 6. In the long term, no relevant differences in terms of water retention capacity were observed for $\mathrm{KC} 40 \% \_20 \% \mathrm{~V}$ and $\mathrm{KC} 40 \% \_40 \% \mathrm{~V}$ treated samples, especially in the higher suction range, as observed for the cement treated samples.

Comparison of water retention curves of cement treated and lightweight cemented samples at fixed curing time (i.e. 30 and 90 days) are shown in Figure 7. No relevant changes of water retention properties are observed for lightweight samples compared to cement treated samples, regardless the curing time. Addition of air foam leads to an increase of the porosity of samples without altering soil matrix microstructure. Therefore, water retention capacity of treated samples is unaffected

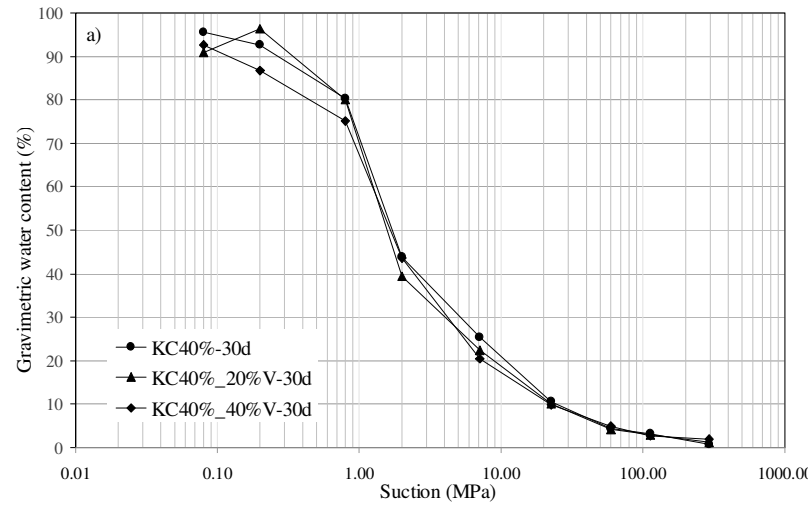

by the addition and amount of foam, as evidenced by the investigations at volume scale level (Fig. 7).

This is confirmed by SEM observations of cementtreated and lightweight cemented samples shown in Figure 8. The soil matrix is made up of an arrangement of kaolinite particles or group of particles, embedded in a network of $\mathrm{C}-\mathrm{S}-\mathrm{H}$ phases. No major changes are observed in the soil matrix for either cement-treated or lightweight cemented samples, regardless of air foam content. An insight into the effects of mixing foam into soil- cement-water slurry with respect to distribution and size of voids is shown in Figures 9 and 10, where SEM observations of lightweight cemented, namely $\left(\mathrm{KC} 40 \% \_20 \% \mathrm{~V}\right.$ and $\left.\mathrm{KC} 40 \% \_40 \% \mathrm{~V}\right)$ samples are respectively reported. At lower magnifications (Fig. 9), the effect of air foam is clearly evidenced by the footprint of air bubbles on the surface of lightweight samples as a consequence of matrix displacement during mixing, whose extent and frequency increase with the rise in air foam content. The soil matrix forms the subspherical limit surface of air bubble footprints, as shown in Figure 10. This structure governs the water retention properties of the lightweight cemented samples.

Fig. 7. Water retention curves of cement treated and lightweight cemented samples: a) after 30 days of curing; b) after 90 days of curing.
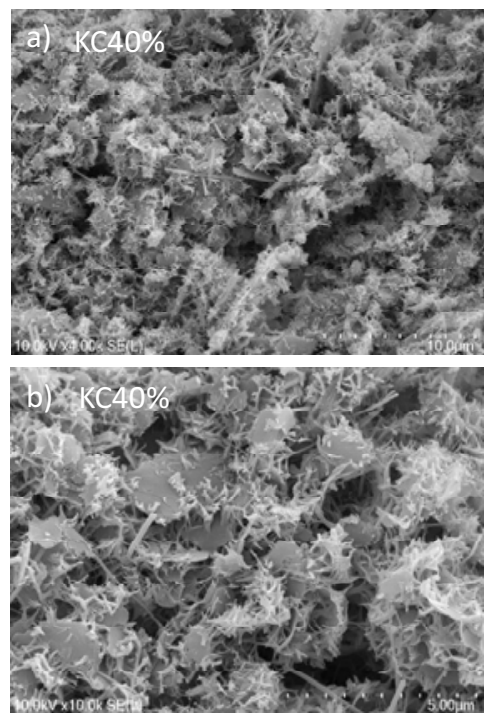
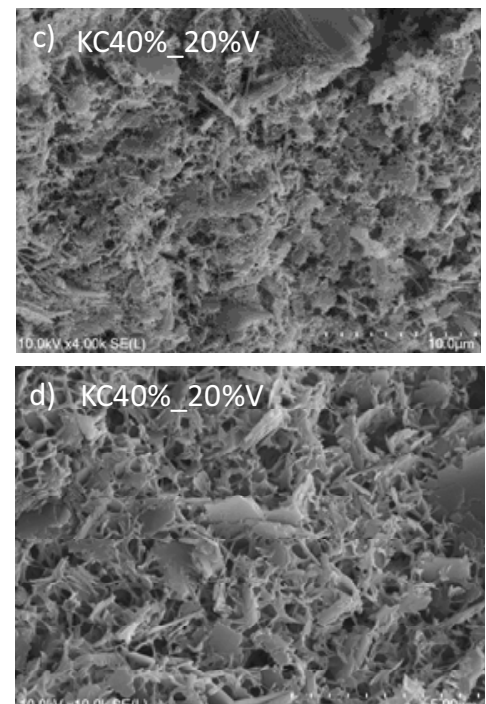
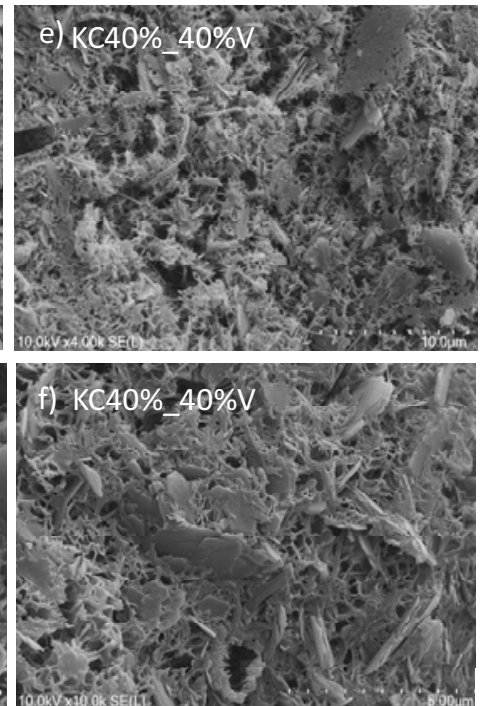

Fig. 8. SEM observations on $\mathrm{KC} 40 \%$ (a, b); KC40\%_20\%V (c, d); KC40\%_40\%V (e, f). 

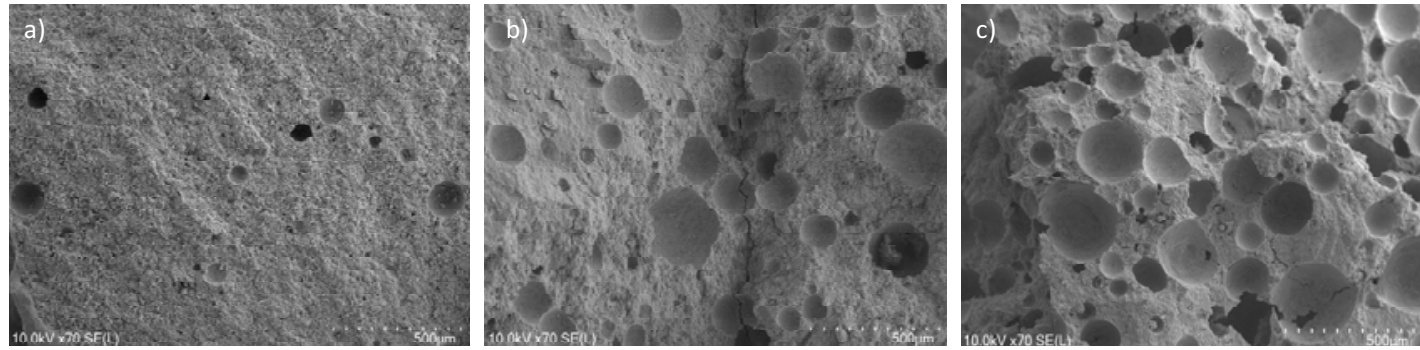

Fig. 9. SEM observations on KC40\% (a); KC40\%_20\%V (b); KC40\%_40\%V (c) [13].
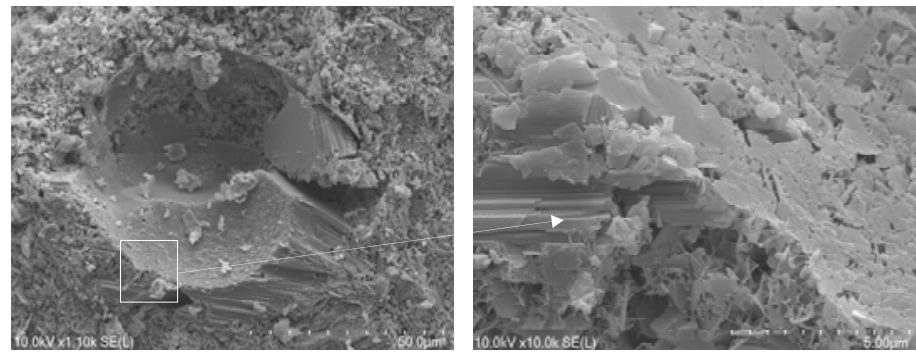

Fig. 10. SEM observations of lightweight cemented sample (KC40\%_40\%V): details of air bubble footprint surface [13].

\section{Conclusions}

In the paper, an insight into the water retention properties of cement treated and lightweight cemented soil has been presented. This work, aimed at determining the suction range corresponding to a significant change in water content, is preliminary for the further study on the durability properties of LWCS subjected to wetting and drying cycles. The effects of foam content and curing time have been considered in the experimental investigation. In the long term, water retention capacity of treated samples is slightly affected by curing time, as a result of the slight chemo-physical evolution of the system in terms of hydrated phases formed. Comparison of water retention curves of cement treated and lightweight cemented samples at fixed curing time allows to highlight the effects of air foam contents on the hydraulic properties of treated soil. Test results evidence how the addition of air foam does not affect water retention capacity of treated samples. As shown by SEM observations, large voids are present in the samples as footprints of air bubbles upon mixing, leading to an increase of the porosity of samples but without altering the soil matrix, which in turn governs the water retention capacity of soil.

\section{Acknowledgements}

The project has received funding from the European Union's Horizon 2020 research and innovation programme under the Marie Sklodowska-Curie grant agreement No 778120.

\section{References}


Notes in Civil Engineering, vol 40. Springer, Cham (2020)

13. E. Vitale, D. Deneele, G. Russo, D. De Sarno, M. V. Nicotera, R. Papa, G. Urciuoli, Acta Geotech. https://doi.org/10.1007/s11440-019-00797-8 (2019)

14. S. L. Barbour, Can. Geotech. J. 35, No. 5, pp. 873894 (1998)

15. D. G. Fredlund, Can. Geotech. J. 37, No. 5, pp. 963986 (2000)

16. G. Stoltz, O. Cuisinier, F. Masrouri, Applied Clay Science 61, 44-51 (2012) 